\title{
The effect of smoking on lung function: a clinical study of adult-onset asthma
}

\author{
Minna Tommola ${ }^{1}$, Pinja Ilmarinen ${ }^{1}$, Leena E. Tuomisto ${ }^{1}$, Jussi Haanpää², \\ Terhi Kankaanranta ${ }^{3}$, Onni Niemelä ${ }^{4}$ and Hannu Kankaanranta ${ }^{1,5}$
}

\begin{abstract}
Affiliations: ${ }^{1}$ Dept of Respiratory Medicine, Seinäjoki Central Hospital, Seinäjoki, Finland. ${ }^{2}$ Dept of Clinical Physiology, Seinäjoki Central Hospital, Seinäjoki, Finland. ${ }^{3}$ Police University College, Tampere, Finland. ${ }^{4}$ Dept of Laboratory Medicine and Medical Research Unit, Seinäjoki Central Hospital, Seinäjoki, Finland. ${ }^{5}$ Dept of Respiratory Medicine, University of Tampere, Tampere, Finland.
\end{abstract}

Correspondence: Minna Tommola, Dept of Respiratory Medicine, Seinäjoki Central Hospital, 60220 Seinäjoki, Finland. E-mail: minna.tommoladepshp.fi

ABSTRACT The aim of this study was to evaluate the effect of smoking on lung function decline in adult-onset asthma in a clinical, 12-year follow-up study.

In the Seinäjoki Adult Asthma Study, 203 patients were followed for 12 years (1999-2013) after diagnosis of new-onset adult asthma. Patients were divided into two groups based on smoking history: $<10$ or $\geqslant 10$ pack-years. Spirometry evaluation points were: 1) baseline, 2) the maximum lung function during the first 2.5 years after diagnosis (Max0-2.5) and 3) after 12 years of follow-up.

Between Max0-2.5 and follow-up, the median annual decline in absolute forced expiratory volume in $1 \mathrm{~s}$ (FEV1) was $36 \mathrm{~mL}$ in the group of patients with $<10$ pack-years of smoking and $54 \mathrm{~mL}$ in those with smoking history $\geqslant 10$ pack-years $(p=0.003)$. The annual declines in FEV1 $\%$ pred $(p=0.006)$, forced vital capacity $(\mathrm{FVC})(\mathrm{p}=0.035)$ and FEV1/FVC $(\mathrm{p}=0.045)$ were also accelerated in the group of patients with $\geqslant 10$ pack-years smoked. In multivariate regression analysis, smoking history $\geqslant 10$ pack-years became a significant predictor of accelerated decline in FEV1.

Among patients with clinically defined adult-onset asthma, smoking history $\geqslant 10$ pack-years is associated with accelerated loss of lung function.

@ERSpublications

In adult-onset asthma, smoking history $\geqslant 10$ pack-years is associated with accelerated loss of lung function http://ow.ly/zZep302fJob

This article has supplementary material available from erj.ersjournals.com

Received: April 292016 | Accepted after revision: July 092016 | First published online: Sept 222016

Clinical trial: This study is registered at www.clinicaltrials.gov with identifier number NCT02733016.

Support statement: This study was supported by the Finnish Anti-Tuberculosis Association Foundation (Helsinki, Finland), Tampere Tuberculosis Foundation (Tampere, Finland), Jalmari and Rauha Ahokas Foundation (Helsinki, Finland), the Research Foundation of the Pulmonary Diseases (Helsinki, Finland), the Competitive State Research Financing of the Expert Responsibility Area of Tampere University Hospital (Tampere, Finland), and the Medical Research Fund of Seinäjoki Central Hospital (Seinäjoki, Finland). None of the sponsors had any involvement in the planning, execution, drafting or write-up of this study. Funding information for this article has been deposited with the Open Funder Registry.

Conflict of interest: Disclosures can be found alongside this article at erj.ersjournals.com

Copyright OERS 2016 


\section{Introduction}

Asthma is a heterogenic disease that has recently been shown to consist of multiple different phenotypes $[1,2]$, which have been identified by cluster analyses based on different clinical features. Age at onset of asthma has been found to be a key factor in distinguishing asthma phenotypes [1]. Early-onset disease is associated with more atopy and allergies than late- or adult-onset asthma. Suggested adult-onset asthma phenotypes are exercise-induced, obesity-related, late-onset eosinophilic (often severe) and smoking-related neutrophilic asthma [1-3]. Most previous studies on asthma have focused mainly on allergic early-onset asthma starting in childhood, but the long-term prognosis of adult-onset asthma is still unknown. However, the limited data suggest that the prognosis of adult-onset asthma is not good, with only $3-4.8 \%$ of patients being in remission after 5 years of diagnosis [4]. Smokers have generally been excluded from studies of asthma because of the concern of possible chronic obstructive pulmonary disease (COPD) influencing the results. Therefore, relatively little is known about the relationship between asthma and smoking.

Smoking among patients with asthma is almost as frequent as in the general population and $26 \%$ of patients with asthma are active smokers [5]. Smoking is associated with increased severity of asthma $[6,7]$, worse asthma-specific quality of life [7, 8], and a greater risk of unscheduled healthcare visits [8] and hospitalisation for asthma [7,9]. Smoking changes the type of asthmatic inflammation towards more neutrophilic $[8,10,11]$ and the response to corticosteroids is attenuated in smokers with asthma [12-15]. Smoking increases the risk of developing asthma [16], especially in allergic patients [17]. While adverse effects of smoking on asthma control and severity are established, less is known about the association between the duration of smoking and dose-effect relationships between smoking and lung function $[6,18]$.

The effect of smoking on lung function in clinical asthma is still mainly unknown. In population-based studies active cigarette smoking is suggested to have a negative effect on lung function in patients with asthma [19-24]. However, in these studies with self-reported asthma [19, 21-24], or self-reported doctor-diagnosed asthma [20], the follow-up was not started when asthma was diagnosed. In addition, the baseline of the most pioneering studies reaches back to years before the widespread use of inhaled corticosteroids $[19,20]$. Furthermore, the use of asthma diagnosis made by self-reporting questionnaires by patients may lead to misclassification of asthma. However, negative studies, in which no relationship between smoking and lung function decline was reported, also exist [25, 26]. Therefore, the effect of smoking on lung function decline in clinically defined patients with asthma still remains controversial, despite the pioneering population-based studies. In particular, the long-term effect of smoking on adult-onset asthma remains unknown. This study addresses the gap in the literature and increases our knowledge by evaluating the effect of tobacco smoking on lung function decline in a well-defined, clinical cohort of patients with new-onset asthma diagnosed at adult age.

\section{Methods}

\section{Study population and design}

The Seinäjoki Adult Asthma Study (SAAS) is a single-centre (Dept of Respiratory Medicine, Seinäjoki Central Hospital, Seinäjoki, Finland) 12-year follow-up study, in which 257 patients were diagnosed to have new-onset adult asthma during the period 1999-2002. The study protocol and the inclusion and exclusion criteria have been published previously [27]. Patients were recruited from the diagnostic visit and the diagnosis of new-onset asthma was made by a respiratory physician. Diagnosis was based on typical symptoms and confirmed by objective lung function measurements [27]. Smokers (current or ex-) were not excluded. Most patients were therapy-naive ( $92 \%$ not on inhaled steroids at the time of diagnosis) and the anti-inflammatory therapy was started immediately after the baseline visit. After a mean (range) follow-up of $12.2(10.8-13.9)$ years a total of 203 patients $(79 \%)$ returned to a control visit. Blood samples were collected (to determine neutrophil and eosinophil counts), and fraction of exhaled nitric oxide (FeNO) was measured at the follow-up visit. During the follow-up patients were actively treated for their asthma according to Finnish Asthma Programme guidelines [28]. Written informed consent was obtained to a study protocol approved by the Ethics committee of Tampere University Hospital, Tampere, Finland (R12122).

\section{Lung function evaluation points}

Lung function measurements were performed with a spirometer (Vmax Encore 22; Viasys Healthcare, Palm Springs, CA, USA) that was calibrated daily. Finnish reference values were used [29]. After the initiation of asthma therapy, only pre-bronchodilator spirometry was measured on most of the patients and therefore we chose the changes in pre-bronchodilator spirometry values for evaluation throughout the study. Lung function measurement points were: 1) baseline (i.e. time of asthma diagnosis), 2) the maximum lung function (Max0-2.5) during the first 2.5 years after diagnosis (i.e. after start of anti-inflammatory therapy) based on the highest pre-bronchodilator forced expiratory volume in $1 \mathrm{~s}$ (FEV1) \% pred and 3) after 12 years of follow-up (figure 1). Lung function measurements after the diagnosis of asthma were taken while patients were on medication, without pauses or withholding on the therapy. 


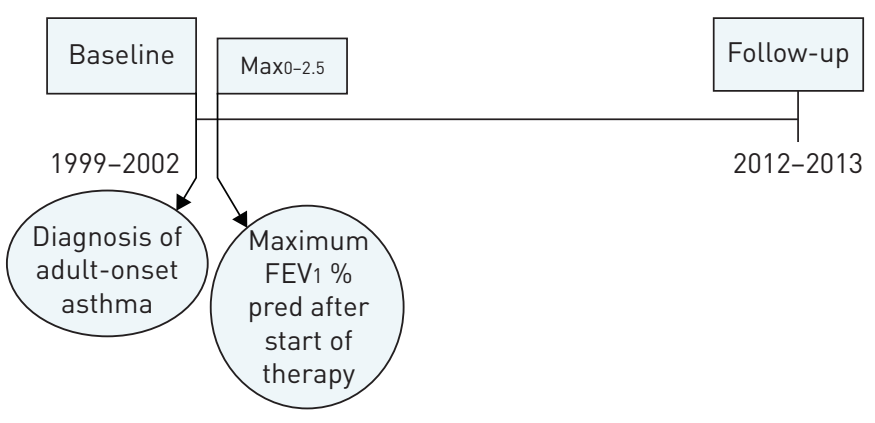

FIGURE 1 Measurement points of spirometry. Maxo-2.5: point of highest lung function (forced expiratory volume in $1 \mathrm{~s}$ (FEV 1 \% pred) during the first 2.5 years after baseline.

\section{Assessment of smoking}

Smoked pack-years $\left(20\right.$ cigarettes $\cdot$ day $^{-1}$ for 1 year) were evaluated both at the baseline and follow-up visits, and patients were divided into two groups based on smoked pack-years: $<10$ and $\geqslant 10$ pack-years. The group of patients that had smoked $\geqslant 10$ pack-years by the follow-up visit was further divided into two groups based on whether pack-years increased during the follow-up or not, indicating that patients had either continued smoking or not, respectively. The number of currently smoking subjects in this study was too low to statistically evaluate the differences in lung function decline between the groups of never-, ex- and current smokers.

\section{Statistical analyses}

Continuous data is expressed as mean \pm SD or median (interquartile range (IQR)). Groups were compared by using the t-test, Mann-Whitney rank sum test or Chi-squared test. Comparisons between three groups were done by one-way ANOVA with the Tukey post hoc test, Kruskal-Wallis test or Chi-squared test.

Multiple linear regression analysis was performed to analyse factors associated with FEV1 decline from point of Max0-2.5 to the follow-up visit. The correlation matrix was analysed and explanatory variables not strongly correlated $(\mathrm{R}<0.7)$ were included in the analysis. Simple linear regression analysis, and forward, backward and enter methods, were used for selection of variables to the final model. Outliers were removed to ensure homoscedasticity. Statistical analyses were performed using SPSS Statistics for Windows version 22 (IBM, Armonk, NY, USA). p $<0.05$ was regarded as statistically significant.

\section{Results}

\section{Baseline characteristics}

The baseline characteristics of the study population $(n=203)$ are shown in table 1 . The median time from baseline to the point of maximum spirometry (Max0-2.5) was 0.6 years (range 0.0-2.4 years), and the median (IQR) increase in FEV1 between baseline and Max0-2.5 was 260 (70-575) mL. The baseline characteristics of the whole cohort $(n=257)$ and those who were lost to follow-up are shown in online supplementary table S1.

To evaluate the effect of smoked pack-years on lung function, patients were divided to groups based on those who had smoked $<10$ or $\geqslant 10$ pack-years at follow-up. The baseline characteristics and detailed smoking characteristics of the groups divided by smoked pack-years are shown in online supplementary table S2. At baseline, patients who had smoked $\geqslant 10$ pack-years were older and more obese. The number of patients who had a post-bronchodilator $\mathrm{FEV} 1 / \mathrm{FVC}$ ratio $<0.7$ at baseline was higher in the group of patients who had smoked $\geqslant 10$ pack-years (online supplementary table S2).

\section{Effect of smoked pack-years on lung function}

Most of the patients were therapy-naive at the baseline visit. Evaluating the effect of smoking on lung function in patients with asthma by comparing the values between the baseline and follow-up visits would be complicated by the effect of asthma therapy started at the baseline visit. Thus, we decided to evaluate the effect of smoking on lung function decline, by measuring the change between the highest lung function measurement available (as judged by the highest pre-bronchodilator FEV1 \% pred) during first 2.5 years after the diagnosis (Max0-2.5) and follow-up. The annual decline in lung function as measured by FEV1 (mL·year ${ }^{-1}$ or \% pred.year ${ }^{-1}$ ) or FVC $\left(\mathrm{mL} \cdot \mathrm{year}^{-1}\right.$ ) between Max0-2.5 and follow-up was significantly more rapid in the group of patients who had smoked $\geqslant 10$ pack-years as compared with those who had smoked $<10$ pack-years. In addition, the decline in the FEV1/FVC ratio was accelerated in the group of patients with $\geqslant 10$ pack-years smoked (table 2 and figure 2 ). 


\begin{tabular}{|c|c|c|c|}
\hline & Baseline & Max0-2.5 & Follow-up \\
\hline Age years & $46.0 \pm 13.7$ & $46.7 \pm 13.7$ & $58.2 \pm 13.6$ \\
\hline Male & 85 (41.9) & 85 (41.9) & 85 (41.9) \\
\hline BMI $\mathrm{kg} \cdot \mathrm{m}^{-2}$ & $27.1(24.1-29.7)$ & $26.9(23.9-29.6)$ & $28.1(24.4-31.2)$ \\
\hline \multicolumn{4}{|l|}{ Smoking status } \\
\hline Never-smoker & 100 (49.3) & & 96 (47.3) \\
\hline Ex-smoker & $67(33.0)$ & & 77 (37.9) \\
\hline Current smoker & $36(17.7)$ & & 30 (14.8) \\
\hline Pack-years ${ }^{\#}$ & $11(5-20)$ & & $16(7-30)$ \\
\hline D. \% pred & $96.9 \pm 18.9$ & & $93.4 \pm 17.7$ \\
\hline D.VA \% pred & $100.4 \pm 18.4$ & & $95.2 \pm 16.3$ \\
\hline Daily use of ICS & $16(8.0)$ & $188(96.4)$ & $155(76.4)$ \\
\hline \multicolumn{4}{|c|}{ Pre-bronchodilator lung function } \\
\hline FEV1 L & $2.85(2.33-3.32)$ & $3.19(2.60-3.87)$ & $2.64(2.17-3.16)$ \\
\hline FEV1 \% pred & $82.8(71.0-92.2)$ & $91.0(83.0-102.0)$ & $86.0(76.0-96.0)$ \\
\hline FEV $1 / F V C$ & $0.75(0.69-0.80)$ & $0.79(0.73-0.83)$ & $0.73(0.66-0.79)$ \\
\hline FVC L & $3.73(3.18-4.44)$ & $4.07(3.40-4.91)$ & $3.66(3.12-4.38)$ \\
\hline FVC \% pred & $90.3(79.8-100.4)$ & $97.3(87.8-105.9)$ & $96.0(87.0-106.0)$ \\
\hline \multicolumn{4}{|c|}{ Post-bronchodilator lung function } \\
\hline FEV1 L & $3.02(2.51-3.55)$ & & $2.75(2.27-3.31)$ \\
\hline FEV $1 \%$ pred & $88.0(76.6-98.9)$ & & $90.0(80.0-98.0)$ \\
\hline FEV $1 / F V C$ & $0.79(0.74-0.83)$ & & $0.75(0.69-0.80)$ \\
\hline FVC L & 3.85 (3.28-4.52) & & $3.77(3.16-4.43)$ \\
\hline FVC \% pred & $94.0(82.0-102.1)$ & & 98.5 (88.0-107.3) \\
\hline $\mathrm{FEV}_{1} / \mathrm{FVC}<0.7$ & $31(16.3)$ & & $54(26.6)$ \\
\hline Atopy ${ }^{\pi}$ & 68 (37.2) & & \\
\hline
\end{tabular}

Data are presented as mean $\pm \mathrm{SD}, \mathrm{n}(\%)$ or median (interquartile range). Max0-2.5: point of highest lung function (forced expiratory volume in $1 \mathrm{~s}$ (FEV 1 ) \% pred) during the first 2.5 years after baseline; BMI: body mass index; $D \mathrm{~L}$ : diffusing capacity of the lung; $V_{\mathrm{A}}$ : alveolar volume; ICS: inhaled corticosteroids; FVC: forced vital capacity. ${ }^{\#}$ : ex- and current smokers; ${ }^{\text {ๆ: }}$ as defined by positive skin-prick test towards common aeroallergen.

To exclude the possibility that smoking cessation leads to a further increase in lung function between baseline and Max0-2.5, which could explain accelerated decrease in lung function in ex-smokers with $\geqslant 10$ pack-years, the lung function level (online supplementary table S3) and increase in lung function between baseline and Max0-2.5 (online supplementary table S4) were evaluated. However, there was no evidence of higher levels of lung function at Max0-2.5 or enhanced response to therapy in ex-smokers as compared to never-smokers (online supplementary tables S3 and S4). Furthermore, there is a possibility that inclusion of current smokers in the analysis may lead to a bias. However, when current smokers were excluded from the analysis, the results remained similar, i.e. ex-smokers with $\geqslant 10$ pack-years of smoking showed accelerated decline in lung function (online supplementary table S5). To exclude the possibility that patients having COPD with reversibility of the airways could affect the results, patients with diffusing capacity of the lung for carbon monoxide (DLCO) $\leqslant 90 \%$ predicted [30], FEV1/FVC $<0.7$ and smoking history $\geqslant 10$ pack-years were

\begin{tabular}{|c|c|c|c|}
\hline & $<10$ pack-years & $\geqslant 10$ pack-years & p-value \\
\hline Subjects & 124 & 65 & \\
\hline$\Delta$ FEV1 mL-year ${ }^{-1}$ & $-36.1(-60.7--21.6)$ & $-54.1(-73.2--32.6)$ & $0.003^{\#}$ \\
\hline$\Delta$ FEV $1 \%$ pred-year $^{-1}$ & $-0.34(-1.04-0.34)$ & $-0.75(-1.25--0.23)$ & $0.006^{\#}$ \\
\hline$\Delta$ FEV1/FVC-year ${ }^{-1}$ & $-0.004(-0.007--0.002)$ & $-0.006(-0.009--0.003)$ & $0.045^{\#}$ \\
\hline$\Delta \mathrm{FVC} \mathrm{mL} \cdot$ year $^{-1}$ & $-27.6(-54.9--6.8)$ & $-41.7(-63.2--20.8)$ & $0.035^{\#}$ \\
\hline$\Delta$ FVC $\%$ pred-year ${ }^{-1}$ & $0.05(-0.68-0.78)$ & $-0.12(-0.62-0.44)$ & 0.411 \\
\hline
\end{tabular}

Data are presented as $\mathrm{n}$ or median (interquartile range), unless otherwise stated. Max0-2.5: point of highest lung function (forced expiratory volume in $1 \mathrm{~s}$ (FEV1) \% pred) during the first 2.5 years after baseline; FVC: forced vital capacity. "\# statistically significant at $p<0.05$. 


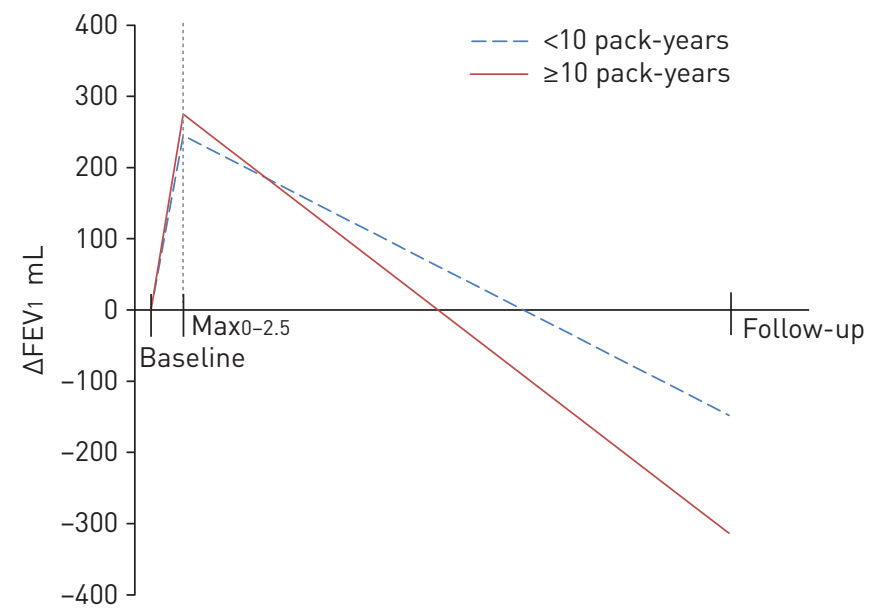

FIGURE 2 Schematic presentation of the changes in forced expiratory volume in $1 \mathrm{~s}(\mathrm{FEV}$ ) $(\mathrm{mL})$ during 12 years of follow-up (see figure 1 for timescale) in the groups of $<10$ or $\geqslant 10$ pack-years. Model based on group medians. Max0-2.5: point of highest lung function (FEV $1 \%$ pred) during the first 2.5 years after baseline. $\mathrm{p}=0.003$ for the annual change in FEV1 between Max0-2.5 and follow-up visit.

excluded. However, after this exclusion, the decline in lung function remained significantly more rapid in those patients with $\geqslant 10$ pack-years of smoking (online supplementary table S6).

\section{The effect on lung function when smoking continues}

In $\mathrm{COPD}$, it has been proposed that accelerated lung function decline may continue even after smoking cessation [31]. To evaluate whether the accelerated loss of lung function in patients with asthma having smoked $\geqslant 10$ pack-years was related to active smoking, or to history of smoked pack-years, we compared the rate of lung function decline in patients who continued smoking during the follow-up (i.e. pack-years increased) and patients who did not continue smoking after diagnosis. Surprisingly, there were no differences in the rate of lung function decline between these groups (table 3). This suggests that having ever smoked $\geqslant 10$ pack-years is associated with accelerated loss of lung function, despite whether the patient has stopped smoking or not.

Facing a new adult-onset asthma patient at the time of diagnosis

To evaluate the combined effect of asthma therapy and smoking on lung function changes we compared the lung function data between the baseline (i.e. point of diagnosis) and the 12-year follow-up. This comparison closely reflects the situation in which a clinician is facing an adult patient with novel diagnosis of asthma and wondering what will be the future of the patient if he/she is a smoker or not. During the whole 12 years of follow-up from the diagnosis of adult-onset asthma the annual decline in FEV1 \% pred was significantly more rapid in the group of patients who had smoked $\geqslant 10$ pack-years as compared with the group of patients who had smoked $<10$ pack-years (table 4$)$. The difference in the annual decline in absolute FEV $1(\mathrm{~mL})$ was

TABLE 3 Annual change in lung function between Max0-2.5 and follow-up visit in group of patients with $\geqslant 10$ pack-years of smoking, divided further by whether smoking continued after baseline or not

\section{$\geqslant 10$ pack-years, smoking cessation at baseline}

$\geqslant 10$ pack-years, smoking
continued after baseline

$\begin{array}{cc}37 & \\ -54.1(-79.9--38.9) & 0.643 \\ -0.77(-1.20--0.43) & 0.740 \\ -0.005(-0.010--0.002) & 0.286 \\ -41.7(-66.1--25.4) & 0.434 \\ -0.40(-0.75-0.25) & 0.077\end{array}$

p-value

28
$-51.6(-70.3--27.4)$
$-0.64(-1.26--0.12)$
$-0.007(-0.009--0.004)$
$-43.2(-59.6--5.0)$
$-0.04(-0.40-0.90)$

Data are presented as $\mathrm{n}$ or median (interquartile range), unless otherwise stated. Max0-2.5: point of highest lung function (forced expiratory volume in $1 \mathrm{~s}\left(\mathrm{FEV} \mathrm{V}_{1}\right) \%$ pred) during the first 2.5 years after baseline; FVC: forced vital capacity. 


\begin{tabular}{|c|c|c|c|}
\hline & $<10$ pack-years & $\geqslant 10$ pack-years & p-value \\
\hline Subjects & 128 & 65 & \\
\hline$\Delta \mathrm{FEV}_{1} \mathrm{~mL} \cdot \mathrm{year}^{-1}$ & $-16.6(-31.4-3.3)$ & $-25.0(-41.7-0.9)$ & 0.052 \\
\hline$\Delta$ FEV$_{1} \%$ pred-year $^{-1}$ & $0.40(-0.16-1.06)$ & $0.08(-0.48-0.78)$ & $0.022^{\#}$ \\
\hline$\Delta \mathrm{FEV}_{1} / \mathrm{FVC} \cdot$ year $^{-1}$ & $-0.003(-0.006-0.002)$ & $-0.003(-0.007-0.001)$ & 0.452 \\
\hline$\Delta \mathrm{FVC}$ mL-year ${ }^{-1}$ & $-7.7(-32.7-17.2)$ & $-16.6(-44.3-15.7)$ & 0.143 \\
\hline$\Delta \mathrm{FVC} \%$ pred-year $^{-1}$ & $0.59(-0.09-1.28)$ & $0.33(-0.08-1.15)$ & 0.227 \\
\hline
\end{tabular}

Data are presented as $\mathrm{n}$ or median (interquartile range), unless otherwise stated. $\mathrm{FEV}$ 1: forced expiratory volume in $1 \mathrm{~s}$; FVC: forced vital capacity. ${ }^{\#}$ : statistically significant at $p<0.05$.

of a borderline significance towards a more rapid loss of lung function among patients with $\geqslant 10$ pack-years of smoking history. In contrast, there were no statistically significant differences in $\triangle \mathrm{FVC}$ or in $\triangle \mathrm{FEV} 1 / \mathrm{FVC}$ (table 4). When using post-bronchodilator values, the changes in lung function did not become statistically significant (online supplementary table S7). To evaluate whether the accelerated decline in lung function between baseline and follow-up in patients having smoked $\geqslant 10$ pack-years was related to active smoking or to smoked pack-years, we compared the rate of lung function decline in patients who continued smoking during the follow-up (i.e. pack-years increased) with those in whom the number of pack-years did not increase (i.e. ex-smokers and patients who did not continue smoking after diagnosis). However, there were no significant differences between these groups (online supplementary table S8). This suggests that it is ever having smoked $\geqslant 10$ pack-years that is associated with accelerated decline in lung function.

\section{Determinants of lung function decline}

Multiple linear regression analysis revealed that significant predictors of absolute FEV1 $(\mathrm{mL})$ decline (from Max0-2.5 to follow-up) were pack-years $\geqslant 10, \mathrm{FEV} 1 \%$ pred at baseline, $\Delta \mathrm{FEV} 1 \mathrm{~mL}$ (baseline to Max0-2.5), FeNO $>20 \mathrm{ppb}$ at follow-up and blood eosinophils at follow-up. A trend towards being predictors of FEV1 decline was shown for age, weight gain, use of oral steroid courses during follow-up and female sex. Instead, daily inhaled corticosteroid use at follow-up did not predict annual FEV1 decline (table 5).

\section{Discussion}

We present here the effect of smoking on lung function during a 12-year follow-up of new-onset asthma in adult patients. Cigarette smoking is significantly associated with the accelerated decline in lung function in patients with adult-onset asthma. When smoking history is $\geqslant 10$ pack-years, the annual decline in FEV1 ( $\mathrm{mL}$ and \% pred), FVC $(\mathrm{mL})$ and FEV1/FVC is significantly accelerated as compared with those who have smoked $<10$ pack-years. Smoking history $\geqslant 10$ pack-years is also associated with more rapid loss of lung function, despite whether the patient has stopped smoking or not.

TABLE 5 Predictors of annual decline of forced expiratory volume in $1 \mathrm{~s}$ (FEV $)$ ( $\mathrm{mL}$ ) from Maxo-2.5 to follow-up in multiple linear regression analysis $(n=154)$

FEV1 estimated decline $\Delta \mathrm{mL}(95 \% \mathrm{Cl})$

p-value

$\Delta B M I$ (Maxo-2.5-follow-up)
Age at follow-up
Female sex
$\geqslant 10$ pack-years at follow-up
Log blood eosinophils at follow-up
$\Delta$ FEV $1 \mathrm{~mL}^{\#}$ (baseline-Maxo-2.5)
FEV $\%$ pred $^{\#}$ at baseline
Not daily ICS user at follow-up
FeNo at follow-up $>20$ ppb
Oral steroids during follow-up

$$
\begin{gathered}
-1.37(-2.87-0.13) \\
-0.30(-0.61--0.00) \\
7.64(-1.45-16.72) \\
-12.08(-21.36--2.80) \\
-18.23(-32.23--4.23) \\
-0.04(-0.05--0.03) \\
-0.54(-0.84--0.24) \\
-2.98(-13.36-7.39) \\
-10.70(-20.54--0.86) \\
-7.79(-16.60-1.02)
\end{gathered}
$$

Max0-2.5: point of highest lung function (FEV1 \% pred) during the first 2.5 years after baseline; BMI: body mass index; ICS: inhaled corticosteroids; FeNO: exhaled nitric oxide fraction. ${ }^{\#}$ : pre-bronchodilator values; ף: statistically significant at $p<0.05$. 
Smokers have generally been excluded from studies of asthma, and therefore little is still known about the relationship of asthma and smoking. Several population-based studies have previously suggested a more rapid lung function decline among smoking patients with asthma as compared with nonsmokers [19-24]. Nevertheless, there are no previous clinical, long-term follow-up studies published showing the negative impact of smoking on lung function in asthma. Previous clinical studies have mostly been cross-sectional evaluations of lung function between smokers and nonsmokers without any follow-up [10], or the follow-up period has been short $(2-3$ years) $[18,32]$. Studies with longer follow-up have not reported the effect of smoking on lung function $[6,13]$. In contrast, some negative studies have been published, showing no relationship between smoking and lung function decline $[25,26]$; thus, the effect of smoking on lung function decline in patients with asthma has been controversial. To the best of our knowledge, this is the first clinical study to show the significant negative impact of smoking on long-term lung function decline in a cohort of patients with clinically defined asthma or adult-onset asthma.

Our findings are in line with the results of epidemiologic studies of asthma and smoking. Two of the most recently published population-based studies have reported accelerated loss of lung function in asthmatic individuals who smoke. In the Copenhagen General Population Study, more rapid decline in FEV1 was reported in smoking asthmatics, as compared with never-smokers with asthma, during 4.5 years of follow-up [23]. In a recent epidemiologic study [24], a birth cohort was followed to the age of 38 years. Among young adults with asthma, smoking was associated with lower FEV1/FVC ratio and lower FEV1 values. The results on the decline in FVC vary between studies [23, 24]. In our study of a clinically defined group of patients with adult-onset asthma, we report here a significant negative impact of smoking on lung function in a long-term follow-up, as measured by FEV 1 ( $\mathrm{mL}$ and \% pred), FVC (mL) and FEV1/FVC ratio. Our results thus confirm in patients with clinically defined asthma the relationship between smoking and accelerated lung function decline, an association suggested by the previous epidemiologic studies [23, 24].

Our finding of continuously accelerated rate of lung function decline, even after smoking is stopped, is supported by studies on COPD. The traditional view of the effects of smoking on lung function in COPD is based on the findings of FLETCHER and PETO [33], who propose a reduction of excessive decline in FEV1 after smoking cessation at any state of COPD. However, recent studies of COPD have reported that the most rapid lung function decline may occur already in the early state of the disease and the accelerated decline in FEV1 is present even in the groups of those patients who have stopped smoking [31, 34, 35]. Our study suggests that a similar accelerated decline in lung function already at the early phase is also present in adult-onset asthma patients who smoke. After 10 pack-years smoked, the rate of lung function decline remains accelerated even if smoking is stopped. This greatly emphasises the importance of early intervention to stop smoking before 10 pack-years is reached.

In a multivariate regression analysis we examined the variables associated with $\triangle \mathrm{FEV} 1(\mathrm{~mL})$ between Max0-2.5 and follow-up visit. Smoked pack-years $\geqslant 10$ became a significant variable to explain the decline in absolute FEV1 (mL). Other significant variables to predict the decline in FEV1 were elevated blood eosinophil count and $\mathrm{FeNO}>20 \mathrm{ppb}$ at follow-up, which are known to be related to existing inflammation and more severe asthma [36, 37]. In addition, results of multivariate analysis suggest that those subjects who originally responded well to the asthma therapy (i.e. high increase in FEV1 $\mathrm{mL}$ between baseline and Max0-2.5) also had a more rapid decline in absolute FEV1 $(\mathrm{mL})$ at follow-up. The relevance of this finding still remains unknown. It could indicate bronchial reactivity leading to a tendency of intense reaction both positively to anti-inflammatory therapy but also negatively to irritating agents. Well-preserved lung function at baseline became an unexpected predictor of accelerated loss of lung function. This finding might be explained with lung capacity, as higher FEV1 values at baseline enable larger decline later on. Studies on asthma and obesity have previously shown that loss of weight is associated with an increase in lung function [38]. However, increased age and weight gain were only of borderline significance in explaining more rapid loss of lung function in asthma. It has previously been suggested that severe asthma exacerbations may predict excess lung function decline [39]. We included exacerbations to the multiple linear regression analysis by evaluating if patients had used oral corticosteroid courses during the follow-up or not. In our results the use of oral corticosteroid courses did not become a significant predictor of FEV1 decline, although there was a trend suggesting that exacerbations may predict loss of lung function.

Our study has several strengths. In our real-life clinical cohort, the diagnosis of new-onset adult asthma was made by a respiratory physician. The diagnosis was based on typical symptoms and objective lung function measurements showing reversibility of airway obstruction [27]. The 12-year follow-up is exceptionally long, giving us a strong view of the prognosis of lung function in these patients. The response rate in our study was good as $79 \%$ of patients of the original cohort returned to the follow-up visit. The use of Max0-2.5 as a measurement point enabled us to include the optimal lung function of patients after the functional improvement due to the treatment for asthma was achieved. A period of 2.5 years was chosen to allow time for the therapy to have an effect and to eliminate bias from practical delays (due to hospital or the patient), 
although the maximum lung function was usually achieved in 0.6 years. There remain some limitations in the interpretation of our results. The number of current smokers at follow-up was too low ( $\mathrm{n}=21)$ to statistically evaluate the differences between groups of never-, ex- and current smokers. However, we further analysed the data with current smokers excluded to better understand the differences between neversmokers and ex-smokers (with $\geqslant 10$ pack-years). The main results of these analyses remained the same, showing more rapid loss of lung function among ex-smokers with $\geqslant 10$ pack-years. This indicates that inclusion of current smokers does not lead to biased results. Another limitation is lack of post-bronchodilator spirometry values at the point of Max0-2.5, which led to the use of pre-bronchodilator values throughout the study. We acknowledge that in some patients with asthma, large bronchial reversibility may be observed constantly over time and, furthermore, reversibility of the airways rarely remains constant in a particular patient [40]. Therefore, inevitably using post-bronchodilator values of spirometry would have been more suitable and this is to be considered a limitation of our study. Other limitations of the study are the lack of a control group and lack of data on exposure to second-hand smoke. Our study population was a cohort of real-life clinical asthma patients, including smoking subjects. Therefore, the study cohort includes some patients who could be classified as having the recently defined asthma/COPD overlap syndrome [41, 42]. However, the lung diffusion capacity values of patients were well preserved both at baseline and follow-up, excluding the possibility of significant bias due to emphysema. In addition, variable airway obstruction, a hallmark of asthma [43], was objectively established in every patient at baseline, which leads to exclusion of classic COPD patients with no reversibility of the airways. Furthermore, our main findings remained similar in further analyses when patients with DLCO $\leqslant 90 \%$, combined with smoking history $\geqslant 10$ pack-years and $\mathrm{FEV} 1 / \mathrm{FVC}<0.7$, were excluded.

In conclusion, in patients with new-onset adult asthma, smoking is significantly associated with the decline in lung function. The loss of lung function is more rapid among patients with $\geqslant 10$ smoked pack-years as compared with those who smoked $<10$ pack-years. Furthermore, our results suggest that having ever smoked $\geqslant 10$ pack-years is associated with accelerated decline in lung function and after 10 smoked pack-years the rate of lung function decline remains accelerated, despite whether patient has stopped smoking or not. Our results highlight the importance of smoking cessation interventions at early phase in patients with adult-onset asthma.

\section{Acknowledgements}

We are grateful to Aino Sepponen (Dept of Respiratory Medicine, Seinäjoki Central Hospital, Seinäjoki, Finland) for her input with data management.

\section{References}

1 Wenzel SE. Asthma phenotypes: the evolution from clinical to molecular approaches. Nat Med 2012; 18: 716-725.

2 De Nijs SB, Venekamp LN, Bel EH. Adult-onset asthma: is it really different? Eur Respir Rev 2013; 22: 44-52.

3 Ilmarinen P, Tuomisto LE, Kankaanranta H. Phenotypes, risk factors and mechanisms of adult-onset asthma. Mediators Inflamm 2015; 2015: 514868.

4 Tuomisto LE, Ilmarinen P, Kankaanranta H. Prognosis of new-onset asthma diagnosed at adult age. Respir Med 2015; 109: 944-954.

5 Cerveri I, Cazzoletti L, Corsico AG, et al. The impact of cigarette smoking on asthma: a population-based international cohort study. Int Arch Allergy Immunol 2012; 158: 175-183.

6 Polosa R, Russo C, Caponnetto P, et al. Greater severity of new onset asthma in allergic subjects who smoke: a 10-year longitudinal study. Respir Res 2011; 12: 16.

7 Eisner MD, Iribarren C. The influence of cigarette smoking on adult asthma outcomes. Nicotine Tob Res 2007; 9 : 53-56.

8 Thomson NC, Chaudhuri R, Heaney LG, et al. Clinical outcomes and inflammatory biomarkers in current smokers and exsmokers with severe asthma. J Allergy Clin Immunol 2013; 131: 1008-1016.

9 Kauppi $\mathrm{P}$, Kupiainen $\mathrm{H}$, Lindqvist $\mathrm{A}$, et al. Long-term smoking increases the need for acute care among asthma patients: a case control study. BMC Pulm Med 2014; 14: 119.

10 Boulet L-P, Lemière C, Archambault F, et al. Smoking and asthma: clinical and radiologic features, lung function, and airway inflammation. Chest 2006; 129: 661-668.

11 Chalmers GW, Macleod KJ, Thomson L, et al. Smoking and airway inflammation in patients with mild asthma. Chest 2001; 120: 1917-1922.

12 Chalmers GW, MacLeod KJ, Little SA, et al. Influence of cigarette smoking on inhaled corticosteroid treatment in mild asthma. Thorax 2002; 57: 226-230.

13 Dijkstra A, Vonk JM, Jongepier $\mathrm{H}$, et al. Lung function decline in asthma: association with inhaled corticosteroids, smoking and sex. Thorax 2006; 61: 105-110.

14 Lazarus SC, Chinchilli VM, Rollings NJ, et al. Smoking affects response to inhaled corticosteroids or leukotriene receptor antagonists in asthma. Am J Respir Crit Care Med 2007; 175: 783-790.

15 Tomlinson JE, McMahon AD, Chaudhuri R, et al. Efficacy of low and high dose inhaled corticosteroid in smokers versus non-smokers with mild asthma. Thorax 2005; 60: 282-287.

16 Nakamura K, Nagata C, Fujii K, et al. Cigarette smoking and the adult onset of bronchial asthma in Japanese men and women. Ann Allergy Asthma Immunol 2009; 102: 288-293.

17 Polosa R, Knoke JD, Russo C, et al. Cigarette smoking is associated with a greater risk of incident asthma in allergic rhinitis. J Allergy Clin Immunol 2008; 121: 1428-1434. 
18 Westerhof GA, Vollema EM, Weersink EJ, et al. Predictors for the development of progressive severity in new-onset adult asthma. J Allergy Clin Immunol 2014; 134: 1051-1056.

19 Lange P, Parner J, Vestbo J, et al. A 15-year follow-up study of ventilatory function in adults with asthma. N Engl J Med 1998; 339: 1194-1200.

20 James AL, Palmer LJ, Kicic E, et al. Decline in lung function in the Busselton health study: the effects of asthma and cigarette smoking. Am J Respir Crit Care Med 2005; 171: 109-114.

21 Aanerud M, Carsin A-E, Sunyer J, et al. Interaction between asthma and smoking increases the risk of adult airway obstruction. Eur Respir J 2015; 45: 635-643.

22 Apostol GG, Jacobs DR Jr, Tsai AW, et al. Early life factors contribute to the decrease in lung function between ages 18 and 40: the Coronary Artery Risk Development in Young Adults study. Am J Respir Crit Care Med 2002; 166: 166-172.

23 Colak Y, Afzal S, Nordestgaard BG, et al. Characteristics and prognosis of never-smokers and smokers with asthma in the Copenhagen General Population Study. A prospective cohort study. Am J Respir Crit Care Med 2015; 192: 172-181.

24 Hancox RJ, Gray AR, Poulton R, et al. The effect of cigarette smoking on lung function in young adults with asthma. Am J Respir Crit Care Med 2016; 194: 276-284.

25 Grol MH, Gerritsen J, Vonk JM, et al. Risk factors for growth and decline of lung function in asthmatic individuals up to age 42 years. A 30-year follow-up study. Am J Respir Crit Care Med 1999; 160: 1830-1837.

26 Ulrik CS, Backer V, Dirksen A. A 10 year follow up of 180 adults with bronchial asthma: factors important for the decline in lung function. Thorax 1992; 47: 14-18.

27 Kankaanranta H, Ilmarinen P, Kankaanranta T, et al. Seinäjoki Adult Asthma Study (SAAS): a protocol for a 12-year real-life follow-up study of new-onset asthma diagnosed at adult age and treated in primary and specialised care. NPJ Prim Care Respir Med 2015; 25: 15042.

28 Haahtela T, Klaukka T, Koskela K, et al. Asthma programme in Finland: a community problem needs community solutions. Thorax 2001; 56: 806-814.

29 Viljanen AA, Halttunen PK, Kreus KE, et al. Spirometric studies in non-smoking, healthy adults. Scand J Clin Lab Invest Suppl 1982; 159: 5-20.

30 Amelink M, de Groot JC, de Nijs SB, et al. Severe adult-onset asthma: a distinct phenotype. J Allergy Clin Immunol 2013; 132: 336-341.

31 Drummond MB, Hansel NN, Connett JE, et al. Spirometric predictors of lung function decline and mortality in early chronic obstructive pulmonary disease. Am J Respir Crit Care Med 2012; 185: 1301-1306.

32 O'Byrne PM, Lamm CJ, Busse WW, et al. The effects of inhaled budesonide on lung function in smokers and nonsmokers with mild persistent asthma. Chest 2009; 136: 1514-1520.

33 Fletcher C, Peto R. The natural history of chronic airflow obstruction. Br Med J 1977; 1: 1645-1648.

34 Csikesz NG, Gartman EJ. New developments in the assessment of COPD: early diagnosis is key. Int J Chron Obstruct Pulmon Dis 2014; 9: 277-286.

35 Tantucci C, Modina D. Lung function decline in COPD. Int J Chron Obstruct Pulmon Dis 2012; 7: 95-99.

36 Kim HB, Eckel SP, Kim JH, et al. Exhaled NO: determinants and clinical application in children with allergic airway disease. Allergy Asthma Immunol Res 2016; 8: 12-21.

37 Miranda C, Busacker A, Balzar S, et al. Distinguishing severe asthma phenotypes: role of age at onset and eosinophilic inflammation. J Allergy Clin Immunol 2004; 113: 101-108.

38 Kankaanranta H, Kauppi P, Tuomisto LE, et al. Emerging comorbidities in adult asthma: risks, clinical associations, and mechanisms. Mediators Inflamm 2016; 2016: 3690628.

39 Bai TR, Vonk JM, Postma DS, et al. Severe exacerbations predict excess lung function decline in asthma. Eur Respir J 2007; 30: 452-456.

40 Sharma S, Litonjua AA, Tantisira KG, et al. Clinical predictors and outcomes of consistent bronchodilator response in the childhood asthma management program. J Allergy Clin Immunol 2008; 122: 921-928.

41 Global Initiative for Asthma and Global Initiative for Chronic Obstructive Lung Disease. Diagnosis of Diseases of Chronic Airflow Limitation: Asthma, COPD and Asthma-COPD Overlap Syndrome (ACOS). 2015. www.ginasthma.org Date last accessed: September 21, 2015.

42 Kankaanranta $\mathrm{H}$, Harju $\mathrm{T}$, Kilpeläinen $\mathrm{M}$, et al. Diagnosis and pharmacotherapy of stable chronic obstructive pulmonary disease: the Finnish guidelines. Basic Clin Pharmacol Toxicol 2015; 116: 291-307.

43 Global Initiative for Asthma. Global Strategy for Asthma Management and Prevention. Updated 2015. www.ginasthma.org Date last accessed: September 21, 2015. 